\title{
Cottonseed Trimethylolpropane (TMP) Ester as Lubricant and Performance Characteristics for Diesel Engine
}

\author{
Gulab Siraskar, V. D. Wakchaure, R. S. Jahagirdar, H. U. Tiwari
}

\begin{abstract}
Many researchers have been working on bio-based lubricant which is complete or partial replacement for mineralbased lubricant. Mineral-based lubricant is highly pollutant and possesses environmental threat as it is not biodegradable, in the initial days of the industrial revolution bio-based lubricants were widely used, later it was replaced by more sustainable and easily available but environmental polluting mineral oils, currently due to environmental concerns and scarcity of mineral oils, bio-based lubricant has gained importance. Bio-based lubricants are now a day's used for various applications such as transformer oil and processes where there is complete loss of lubricants. They possess very good properties in such applications, whereas bio-based lubricants are also used internal combustion engines, pure biobased lubricant may not be suitable for long-duration, but genetically and chemically modified bio-based lubricants will be suitable for IC engine. Though bio-based lubricant possesses many good properties as a lubricant for IC engine and various other application, it is still at large to become commercial, more study is required for checking performance of such pure and modified bio-based lubricants oils, in this paper such study of cotton seed Trimethylolpropane (TMP) ester oil and its effects on performance of brake specific fuel consumption (BSFC), brake thermal efficiency (BTh) and emission of gases like hydrocarbon $(\mathrm{HC})$, carbon monoxide (CO), carbon dioxide $\left(\mathrm{CO}_{2}\right)$ nitrogen oxides $\left(\mathrm{NO}_{x}\right)$ are studied, bio-based have poor cold flow properties and oxidation stability to improve these additives are added. The experimental study shows that Cottonseed Trimethylolpropane Ester (CSTE) displays similar characteristics of thermal efficiency, brake specific fuel consumption and emission of gases as compared to mineralbased lubricating oil hence can be used in the IC engine instead of mineral-based lubricants.
\end{abstract}

Keywords : Cottonseed Trimethylolpropane ester (CSTE), Brake thermal efficiency, BSFC, emissions hydrocarbon (HC), carbon monoxide (CO), carbon dioxide $\left(\mathrm{CO}_{2}\right)$, nitrogen oxides $\left(N O_{x}\right)$.

\section{INTRODUCTION}

The combustion of mineral oil lubricants produces particulate matter of zinc, phosphate, calcium, observed quantity in ppm as calcium 1871,

Revised Manuscript Received on February 05, 2020.

* Correspondence Author

Gulab Siraskar, Assistant Professor, Pimpri Chinchwad College of Engineering and Rresearch Ravet, India.

E-mail: gdsiraskar@gmail.com

Dr. V. D. Wakchaure, Head of Department, Department of Mechanical Engineering, Amrutvahini college of Engineering (AVCOE), Sangamner, Savitribai Phule Pune University, Pune, Maharashtra, India.

Dr. R. S. Jahagirdar, Phd Guide at Amrutvahini college of Engineering (AVCOE), Sangamner, Savitribai Phule Pune University, Pune, Maharashtra, India.

Dr. H. U. Tiwari, Principal, Department of Mechanical Engineering, PCCOE\&R, Ravet, Pune.

(C) The Authors. Published by Blue Eyes Intelligence Engineering and Sciences Publication (BEIESP). This is an open access article under the CC BY-NC-ND license (http://creativecommons.org/licenses/by-nc-nd/4.0/) phosphorus 1118, zinc 877,,magnesium 72, boron 32, iron19,copper 18, lead 6, silicon 6, sodium 7, and molybdenum 5, which are very harmful [1]. The bio-based lubricant possess the required properties as lubricants and can be used instead of mineral-based lubricant oils, biobased lubricant oils have desirable properties as it is biodegradable which is required for environmental concern, they also have very good lubrication properties such as viscosity index, high lubricity, and flash point, load carrying capacity is high, which make them suitable as lubricant [2]. Coefficient of friction for coconut oil is lower than 20W50 mineral oil when used in two stroke IC engine, coconut oil shows good boundary condition (tribological properties), however to use coconut oil in IC engine additives are necessary [3]. For bio-based lubricants possess oxidation and low temperature performance problem, which can be solved by chemical modification and additives [4], though there are many good properties of bio-based lubricants, have some disadvantages such as oxidation stability, poor cold flow property, such problems can be solved by chemical modification in which $\beta$ hydrogen of glycerol can be eliminated, double bond can be removed. The carbon chain also having a very important role for lubricant and also which is fatty acid and what polarity [5]. Oleo chemical ester is having the highest degradation rate which are more concern for the biosphere, aquatic life bio-based lubricant has 4 times faster biodegradation rate compared to mineral oils [6]. Schramm has studied the emission of $\mathrm{CO}, \mathrm{CO}_{2}$, and $\mathrm{NO}_{\mathrm{x}}$ on a chassis dynamometer and on-road vehicle, by taking samples periodically and oxidation stability was checked, it was observed that there is no effect on wear as well as exhaust gas emission except little loss in efficiency and small rise in $\mathrm{NO}_{\mathrm{x}}$ emission [7]. The researcher observed that prop ionic ester of methyl hydroxyl oleate has very good oxidation stability at $175^{\circ} \mathrm{C}$, followed by 2-Ethylhexyl ester which is $166{ }^{\circ} \mathrm{C}$ and levulinic ester LMO $162{ }^{\circ} \mathrm{C}$ [8]. Pongamia oil can be used neat as well as blend with mineral oil, it was observed that with neat Pongamia oil in CI engine increases fuel consumption and gives a considerable brake thermal efficiency at high load conditions. Friction power loss is less in blend lubricants [9]. Mehejabben Kotwal and Srinivas Darbha have studied a better and effective way to produce bio based lubricants, they have observed that by using Titanium silicate as catalyst and esterification of oleic acid with glycerol at $453 \mathrm{~K}$ and reaction was carried out at for 3 hours will lead to better yield and solution possess required properties for lubricant [10]. All the above examples show bio-based lubricants can be used alternative to mineral-based lubricant oil, with different bio-based lubricants and different experimental setup. 


\section{Different oils used by researcher.}

\subsection{Sunflower Oil.}

Sunflower oil has better oxidation stability and lubricity as compared to olive oil and high oleic sunflower oil, high oleic sunflower oil is suitable for textile application as lubricants without modification. Sunflower oil is most suitable for chain saws application [11].

\subsection{Soybean Oil.}

Soybean oil is used for dielectric liquid in transformer oil , it has high fire point, flash point so it would be better to increase the life of transformer [12].

\subsection{Palm Oil.}

Palm oil is studied as a lubricant for extrusion process cold forward and minimum quantity lubrication (MQL) on high speed drilling of titanium alloys [13, 14].

\subsection{Rapeseed Oil.}

Experiment on journal bearing was carried on with rapeseed oil as lubricant in journal bearing which shows blend of rapeseed oil with mineral oil even decreases friction even at high temperature [15].

\subsection{Viscosity Of Lubricant Oil.}

Viscosity has crucial properties for lubrication and if it is low it can make metal to metal contact which may lead to wear and tear of contact surface. Viscosity of oil depends on chain length, intermolecular interaction will have more viscosity [16]. Chemically modification will lead to compact structure, two or more double bond decreases viscosity whereas one double bond increases viscosity, degree of unsaturated-ness also affect the viscosity of lubricating oil, for high temperature application epoxidized soybean oil can be used [17].

\subsection{Bio-based Oils As Lubricants In IC Engine.}

\section{6 a) Palm oil used as lubricant in IC engine.}

Many researchers used different bio based lubrication oil in IC engine mostly in blend with mineral oil and compared performance parameters such as brake specific fuel consumption, brake thermal efficiency it was found that these performance is similar with blend of palm oil $25 \%$ with mineral oil and also decrease in emission occurred with palm oil blend [18].

1.6 b) Palm oil has been studied to find tribological properties such as flash, fire, pour points, viscosity, with blend from 25 to $50 \%$ with mineral oil and compared with $100 \%$ mineral oil (MO), the study shows the crude palm oil and blended oils shows good properties and can be used as environmentally friendly oils [19].

1.6 c) Crankcase lubricating oil is used as Karanja oil and its blend with mineral oil, the blend used in 4 stroke diesel engine show better performance than mineral oil so we can use blend of karanja oil with mineral oil for diesel engine for short duration [20].

1.6 d) Pure cotton seed oil is used as lubricant without modification, is studied in internal combustion engine and it is compared with mineral oil, pure cotton seed oil shows similar characteristics to commercial mineral oil for the short duration of 100 hours. After that cottonseed oil gets oxidised and gum like structure is formed when trial was extended and efficiency of engine decreases due in proper lubrication. So pure cottonseed oil is possible to use in internal combustion engine for short duration, whereas for longer duration chemical modification is required [21].

\subsection{Chemical Modification Of Vegetable Oils.}

in case of biolubricant oxidation stability and poor pour point is due to the fatty acid structure as shown in figure.

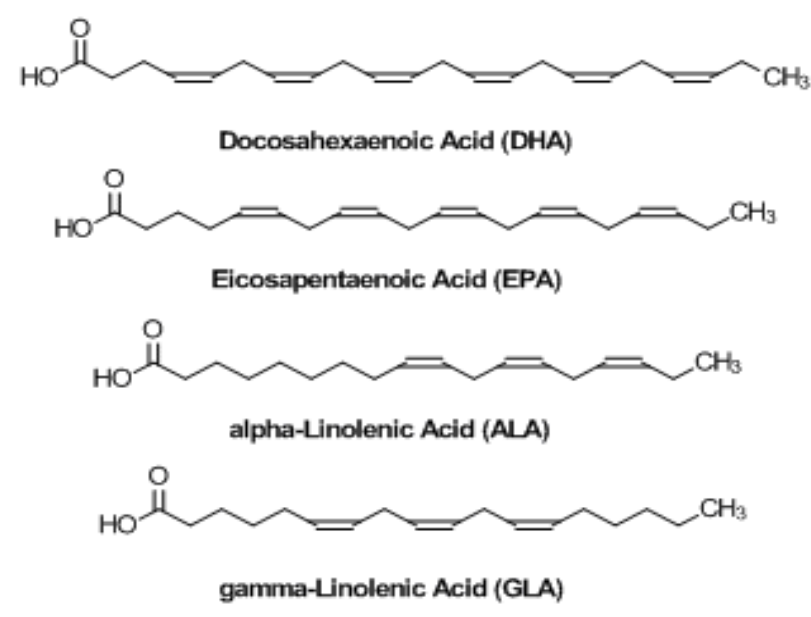

Fig.1 Fatty acid structure.

The double bond and $\beta-\mathrm{CH}$ group of the alcohol react easily with oxygen which lead to oxidation. This can be reduced by transesterification process of trimethylolpropane and methyl ester of bio-based oils which will improve oxidation and pour point of bio based lubricants [22]. The TMP ester and Nano- particle improves coefficient of friction [23].The mid and end chain alkyl group can improve low temperature properties due to steric barrier around individual molecules and restrain crystallisation[24,25]. The palm kernel oil trimethylolpropane (TMP) esters synthesis was performed, temperature and vacuum pressure found to be affecting reaction, approximately $98 \% \mathrm{w} / \mathrm{w}$ conversion to palm kernel TMP triesters yield was obtained [26]. Palm oil TMP esters pour point successfully reduced to $-32{ }^{\circ} \mathrm{C}$ in high oleic content palm oil based TMP esters. Palm oil TMP esters viscosities of high oleic content are almost constant at 50 cSt and VI values are around 199 [27,28].

\subsection{Transesterification Process.}

Transesterification, in the presence of catalyst this triglyceride molecule reacts with methanol to form methyl ester and then to increase thermal stability,

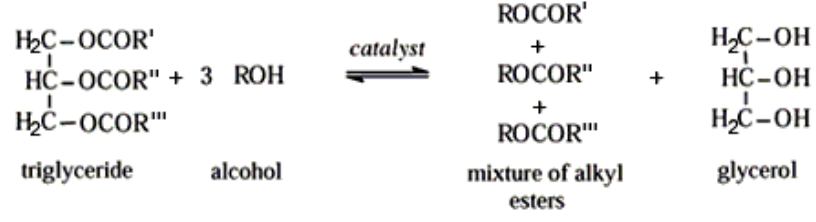

Fig 2. Esterification process.

trimethylolpropane, neopentyl glycol and pentaerythritol can be used in second transesterification process in which hydrogen atom in $\beta$ position is replaced [29-31].

From many years vegetable oils were used as lubricants, whereas later use of vegetable oils became almost absolute due to easy and better availability of mineral-based oils, nowadays fossil fuels based oils are used for lubrication purposes. Currently environmental concern and scarcity of mineral oils have led to consideration of bio-based lubricants [32]. 


\section{SETUP FOR EXPRIMENTATION.}

The engine specification as given in table has all measuring sensor like pressure, air flow, fuel, temperature of engine cooling water in ,out , flue gas exhaust temperature, water for calorimeter, gas entering and leaving in calorimeter with automatic data collection in software and AVL gas analyzer is used to measure exhaust gases, which measure exhaust gases like $\mathrm{HC}, \mathrm{CO}_{2}, \mathrm{CO}, \mathrm{NO}_{\mathrm{x}}$, for loading eddy current dynamometer is used. There are two more additional thermocouples are attached to measure surface temperature of engine and lubricating oil temperature in sump. Experiment is conducted first with mineral oil for 24 hours and then with CSTE, and then average data for 24 hours is compared for mineral oil average data.

\subsection{Engine Data.}

\begin{tabular}{|l|l|}
\hline Make & Kirloskar \\
\hline Model & $\begin{array}{l}\text { Variable compression } \\
\text { ratio }\end{array}$ \\
\hline Power & $3.5 \mathrm{KW}$ \\
\hline Speed & 1500 rpm \\
\hline Cycle & 12 to $18: 1$ \\
\hline Compression & 4 stroke \\
\hline Cooling & 20 mm \\
\hline Cylinder dia & water cooled \\
\hline
\end{tabular}

Table 1 Engine specification.

Fig. 3 shows the experimental setup of diesel engine.
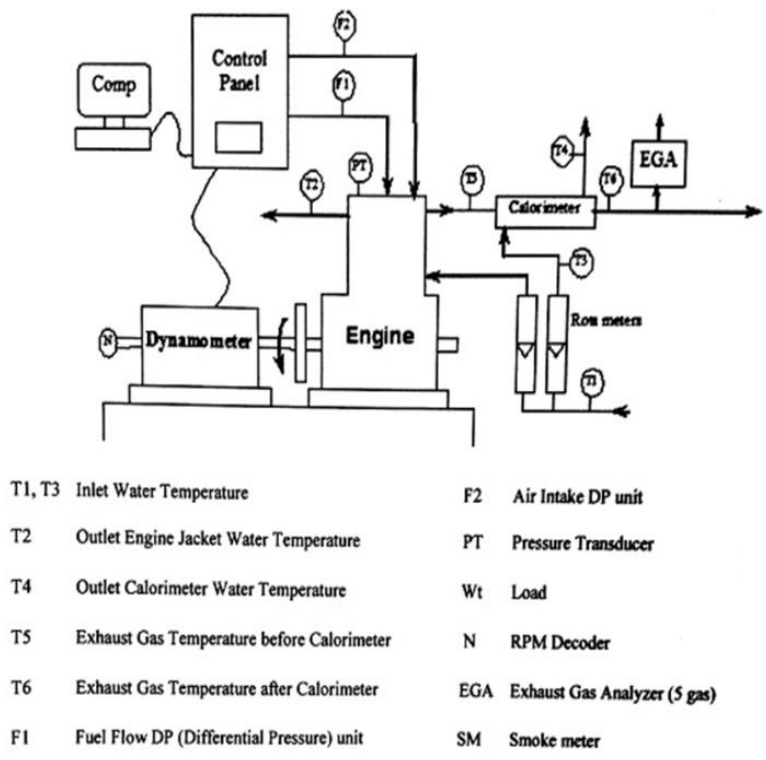

Fig. 3 Engine setup for experiments.

\subsection{Procedures to Prepare Cottonseed TMP Ester (CSTE).}

Cottonseed methyl ester is prepared from cottonseed oil and methanol reaction, cotton seed oil is heated above $100{ }^{\circ} \mathrm{C}$ to remove water residue for 30 minute and then it is reacted with methanol with proportion of 3:1 ( cotton seed oil and methanol) with catalyst as $1 \% \mathrm{NaOH}$, the solution is heated at $60{ }^{0} \mathrm{C}$ for 1.5 hours, this will give us cottonseed methyl ester. The upper layer of methyl ester is used for second reaction with trimethylolpropane (TMP) with proportion of $4: 1$ at $150{ }^{\circ} \mathrm{C}$ for 3 hours and sodium methoxide as catalyst $1 \%$ by weight. Vacuum pump is used to remove methanol and then solution is dried with anhydrous sodium sulfate and filtered to remove unwanted residuals, which gives us cottonseed TMP ester.

Fourier-transform infrared spectroscopy (FTIR) done and FT-IR spectra showed five important absorption bands. It can be observed that the C-H stretching absorption occurs at wavelength 2923.43 as shown in fig. 4, which is an indication of required ester is formed.

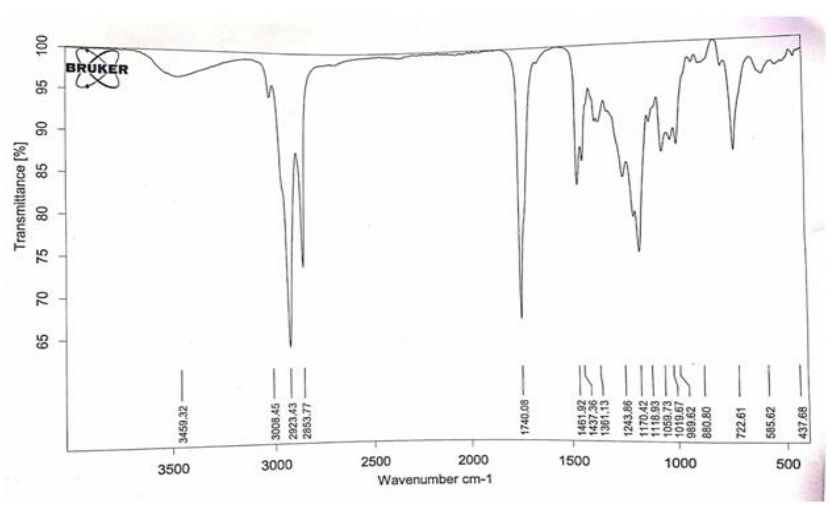

Fig. 4 Fourier-transform infrared spectroscopy (FTIR). 


\subsection{Cotton Seed Oil and Mineral Oil Lubricant Properties.}

Cotton seed oil and mineral lubricant oil properties are measured as shown in table no 2 .

Table. 2 Cotton seed oil and mineral lubricant oil properties.

\begin{tabular}{lccc}
\hline & $\begin{array}{c}\text { Pure } \\
\text { Cottonsee } \\
\text { d oil }\end{array}$ & $\begin{array}{c}\text { Cottonseed } \\
\text { TMP ester }\end{array}$ & $\begin{array}{c}\text { SAE } \\
\text { 20W4 } \\
0\end{array}$ \\
\hline $\begin{array}{l}\text { Kinematic } \\
\text { Viscosity at } 40\end{array}$ & 31.93 & 27.85 & 120 \\
${ }^{\circ} \mathrm{C}(\mathrm{cSt})$ & & & \\
$\begin{array}{l}\text { Kinematic } \\
\text { Viscosity at } 90{ }^{\circ} \mathrm{C} \\
(\mathrm{cSt})\end{array}$ & 6.8 & 4.97 & $14-16$ \\
$\begin{array}{l}\text { Pour point }{ }^{\circ} \mathrm{C} \\
\text { Flash point }\end{array}{ }^{\circ} \mathrm{C}$ & -15 & -10 & -21 \\
\hline
\end{tabular}

\section{TEST RESULT}

The reading for all emission gases taken for $\mathrm{MO}$ oils and lubricant oil is replaced by CSTE and $10 \%$ MO oil blend, table show readings of CSTE and $10 \%$ MO oil blend lubricant for 0 to 24 hours and at every hour, load is changed from 0 to $20 \mathrm{~kg}$ on dynamometer. To increase oxidation stability hydroquinone $0.5 \%$ and viscosity improver vinyl acetate $1 \%$ is used in CSTE and this data is compared with mineral oil lubricant. with the help of engine data collection and software , Brake thermal efficiency and BSFC is measure, also emission data measured on AVL gas analyser.

\subsection{Brake Thermal Efficiency.}

Brake thermal efficiency is the ratio between the measured brake power to the product of the fuel flow rate and its calorific value. The brake thermal efficiency is calculated and plotted against brake mean effective pressure (BMEP) as shown in Figure-3. It can be clearly seen that the brake thermal efficiency of the CSTE is slightly less for the mean effective pressure from 2 bar to 4 bar. Beyond 4 bar mean effective pressure, brake thermal efficiency of the CSTE is almost the same as the brake thermal efficiency obtained from mineral oil. When compared, between neat and esterified forms of cotton seed oil, the esterified form has slightly increased thermal efficiency. Altered chemical properties during esterification improves lubricity of the CSTE oil, thus providing good lubrication to the engine body.

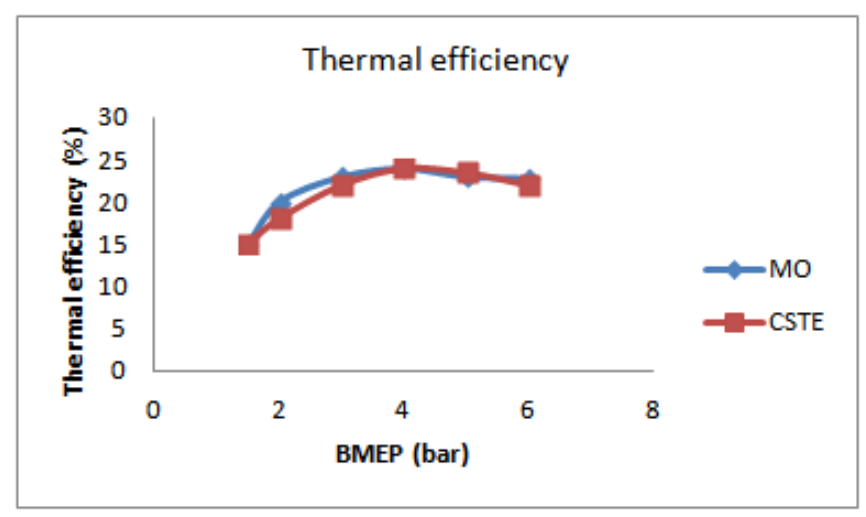

Fig 3. Brake thermal efficiency

\subsection{Brake Specific Fuel Consumption.}

Brake specific fuel consumption (BSFC) is the ratio of the rate of fuel consumption to the brake power produced. it shows how good engine performance so that it is an important parameter. As shown in figure 4 the variation of BSFC with Brake mean effective pressure (BMEP). BSFC for CSTE is almost similar to that of BSFC of mineral oil at the brake mean effective pressure around 2 bar. BSFC for CSTE at the brake mean effective pressure from 2 bar to 4 bar is slightly more than that of BSFC of mineral oil. Whereas, it is seen that BSFC for CSTE is a little lower than BSFC of mineral oil at the brake mean effective pressure from 4 bar to 6 bar. Better lubricating properties of CSTE based lubricants reduce the frictional losses. These factors contribute to the reduction in BSFC.

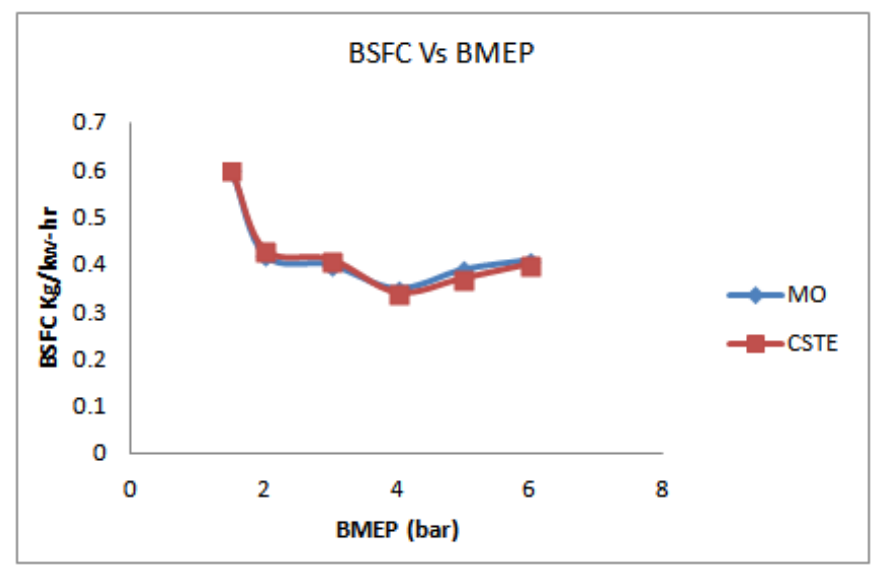

Fig 4. Brake specific fuel consumption

\subsection{Hydrocarbon (HC) emissions.}

$\mathrm{HC}$ emission for MO and CSTE shows in Fig.5, the average value for 24 hours calculated and plotted for the comparison between MO and CSTE, at a speed of $1500 \mathrm{rev} / \mathrm{min}$. The plots shows HC emissions between the two lubricants almost same. The variation of HC emission with load show initial increase then decrease and sharp rise at $20 \mathrm{~kg}$ load. Similar patterns were observed in MO oil lubricants. The plots indicate that $\mathrm{HC}$ emissions peaked at $4 \mathrm{~kg}$ to $8 \mathrm{~kg}$ load and then dropped at $16 \mathrm{~kg}$ load, with further increased at 20 $\mathrm{kg}$ load, corresponding readings in table no 3 . The graphs of the two cases pure MO, blend CSTE shows in fig. 5 very similar values indicating CSTE lubricating oil can be used as substitute to MO lubricants . These readings were taken at different time intervals. 
Table 3. HC emission MO and CSTE average values for 24 hours.

\begin{tabular}{ccc}
\hline Load Kg & $\begin{array}{c}\text { HC MO } \\
(\mathrm{ppm})\end{array}$ & $\begin{array}{c}\text { HC CSTE } \\
(\mathrm{ppm})\end{array}$ \\
\hline 0 & 25 & 18.375 \\
4 & 45.16 & 27.125 \\
8 & 41.66 & 38.91 \\
12 & 27.66 & 33.2 \\
16 & 31 & 31.8 \\
20 & 71 & 84.25 \\
\hline
\end{tabular}

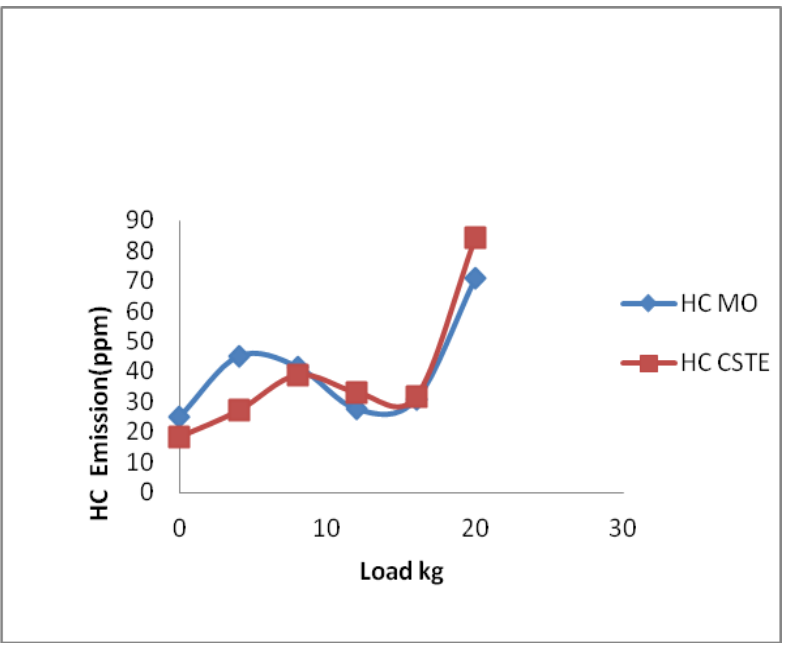

Fig 5. HC emission for MO and CSTE oil.

\subsection{Carbon Monoxide (CO) Emissions.}

The CO emission is special interest for environmental effect and legislation. Fig. 6 shows the plots of $\mathrm{CO}$ emissions of CSTE, and mineral oil lubricant at the speed of 1500 $\mathrm{rev} / \mathrm{min}$ at different loading conditions and corresponding readings in table no 4 . These plots show very less difference in $\mathrm{CO}$ emissions in $\mathrm{MO}$ used lubricant and CSTE lubricants.

Table 4. CO emission MO and CSTE average values for 24 hours.

\begin{tabular}{ccc}
\hline Load Kg & $\begin{array}{c}\text { CO MO } \\
(\mathrm{ppm})\end{array}$ & $\begin{array}{c}\text { CO CSTE } \\
(\mathrm{ppm})\end{array}$ \\
\hline 0 & 0.061 & 0.0366 \\
4 & 0.038 & 0.023 \\
8 & 0.05 & 0.062 \\
12 & 0.0616 & 0.0883 \\
16 & 0.16 & 0.185 \\
20 & 1.53 & 1.4 \\
\hline
\end{tabular}

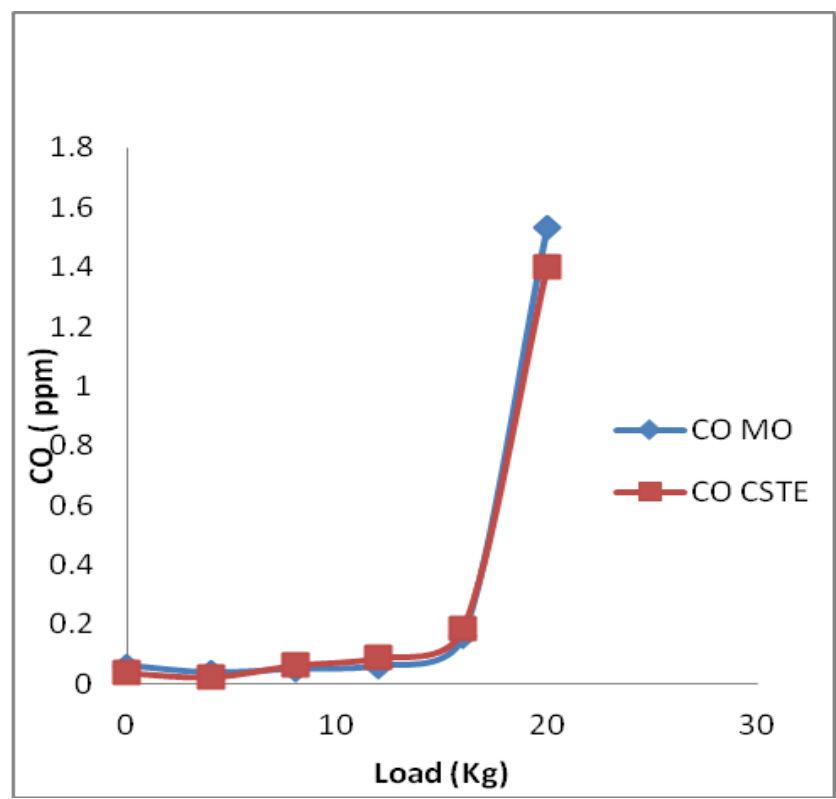

Fig. 6 CO emission for MO and CSTE

The plots showed decreased CO emissions versus load, as load increased when running on CSTE and then peaked at the higher load of $20 \mathrm{~kg}$, the MO lubricant and CSTE oil lubricant shows similar characteristics. The plots show an increase in $\mathrm{CO}$ emissions as the load was increased. Due to air/fuel (A/F) decreases with increasing load for all IC engine CO emission increases with increasing load.

\subsection{Carbon Dioxide (CO2) Emissions.}

Fig. 7 shows 24 hours average of $\mathrm{CO}_{2}$ emission is taken and plotted against load for MO and CSTE oil and corresponding readings in table no 5.

Table 5. CO2 emission MO and CSTE average values for 24 hours.

\begin{tabular}{ccc}
\hline Load kg & $\begin{array}{c}\mathrm{CO}_{2} \mathrm{MO} \\
(\mathrm{ppm})\end{array}$ & $\begin{array}{c}\mathrm{CO}_{2} \mathrm{CSTE} \\
(\mathrm{ppm})\end{array}$ \\
\hline 0 & 1.84 & 1.33 \\
4 & 2.69 & 2.005 \\
8 & 1.99 & 2.39 \\
12 & 2.3 & 2.85 \\
16 & 2.99 & 3.23 \\
20 & 2.65 & 2.62 \\
\hline
\end{tabular}




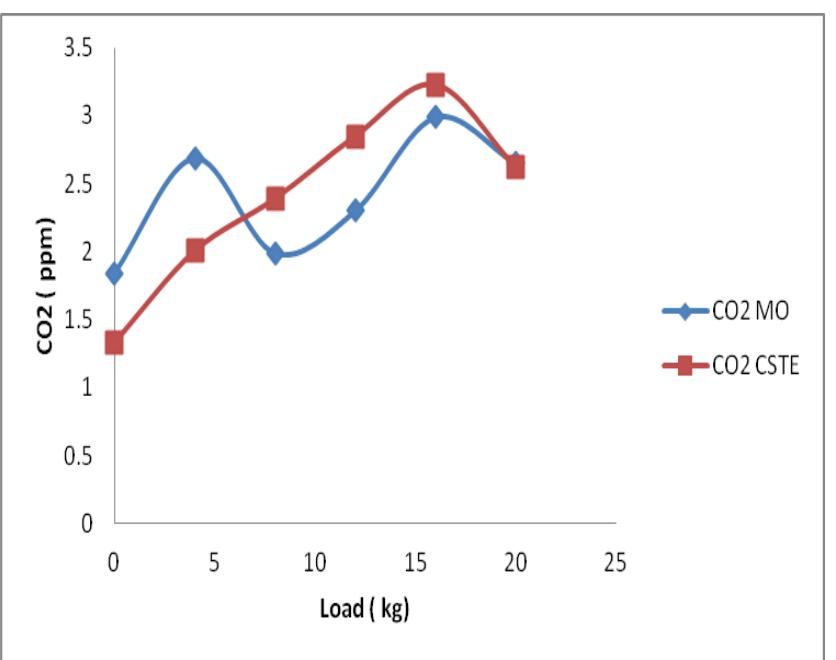

Fig. 7 CO2 emission MO and CSTE.

The MO lubricants show lower values $\mathrm{CO}_{2}$ at 8 to $16 \mathrm{~kg}$ load as compared to CSTE and again it matches with CSTE at $20 \mathrm{~kg}$ load, there is an initial rise of $\mathrm{CO}_{2}$ for $\mathrm{MO}$ oil and then drop and again rise is observed, where are for CSTE it shows continuous rise and at $20 \mathrm{~kg}$ load there is a drop in $\mathrm{CO}_{2}$. There was no significant difference in average $\mathrm{CO}_{2}$ emissions between for MO and CSTE.

\subsection{NOx Emission.}

Fig 12 shows an average of 24 hours $\mathrm{NO}_{\mathrm{x}}$ emission vs different loads for MO and CSTE oil and corresponding values are shown in table no 6 , it shows rise in $\mathrm{NO}_{\mathrm{x}}$ emission as load increases reaches to fix and then drop at highest load of $20 \mathrm{~kg}$. The emission for MO and CSTE oil shows similar nature.

Table 6 NOx emission MO and CSTE average values for 24 hours.

\begin{tabular}{ccc}
\hline Load Kg & $\begin{array}{c}\text { NOx MO } \\
(\mathrm{ppm})\end{array}$ & $\begin{array}{c}\text { NOx CSTE } \\
(\mathrm{ppm})\end{array}$ \\
\hline 0 & 27.33 & 41.83 \\
4 & 108.3 & 94.54 \\
8 & 147.16 & 170.87 \\
12 & 293 & 354.16 \\
16 & 500 & 528.7 \\
20 & 330.5 & 317.04 \\
\hline
\end{tabular}

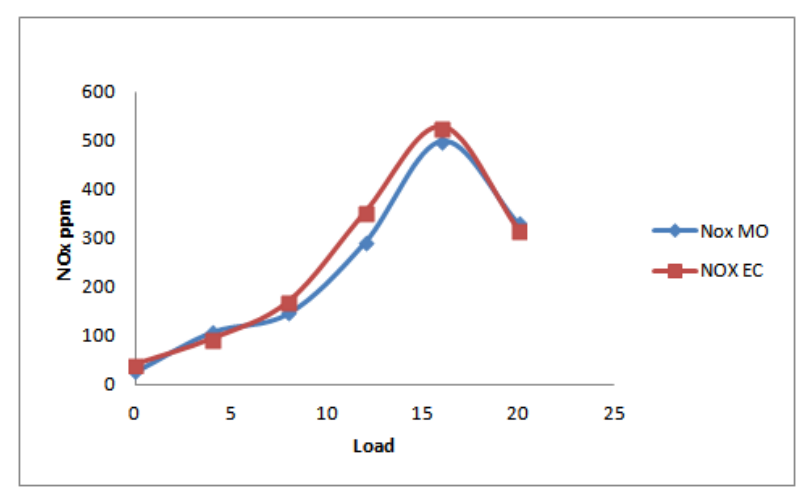

Fig.8 NOx emission for MO and CSTE oil.

\subsection{Fuel consumption.}

Compares fuel consumption by mass of MO lubricant and CSTE lubricants, it is observed that there is a slight increase in consumption which is indicated for reduction in efficiency by 2 to $3 \%$ compared to mineral oil lubricants. This can be improved by adding some additives, in this test additives like hydroquinone and vinyl acetate are used to improve lubricant properties. This efficiency is very good as compared to only pure cotton seed oil used in previous test. The CSTE oil lubricants show results close to mineral oil lubricants.

\subsection{Exhaust temperatures.}

The heat release can be indicated by measuring the exhaust temperature and it is measured at $30 \mathrm{~mm}$ away from the combustion chamber and also effective cooling by lubricating oil. The plot shows the exhaust temperatures of CSTE operation at a speed of $1500 \mathrm{rev} / \mathrm{min}$ were slightly less than MO lubricating oil operation at all load conditions is shown in fig 9.

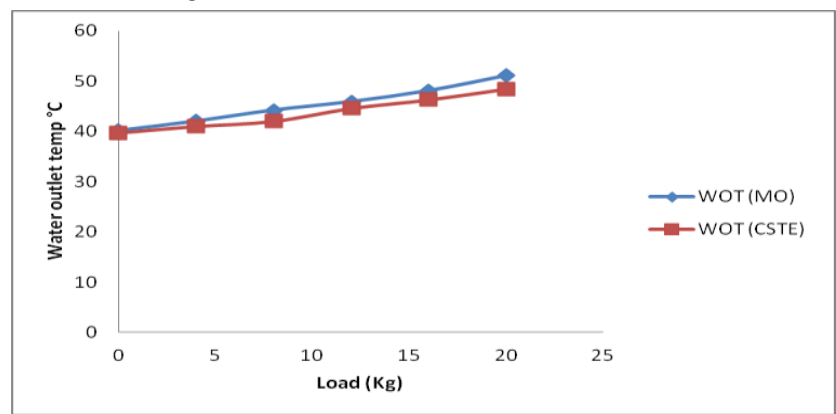

Fig. 9 Exhaust temperatures at different -load conditions.

Engine cooling water temperature by keeping inlet water temperature same, cooling water outlet temperature show similar temperature for mineral oil and TMP ester cotton seed lubricating oil. As shown in fig 10.

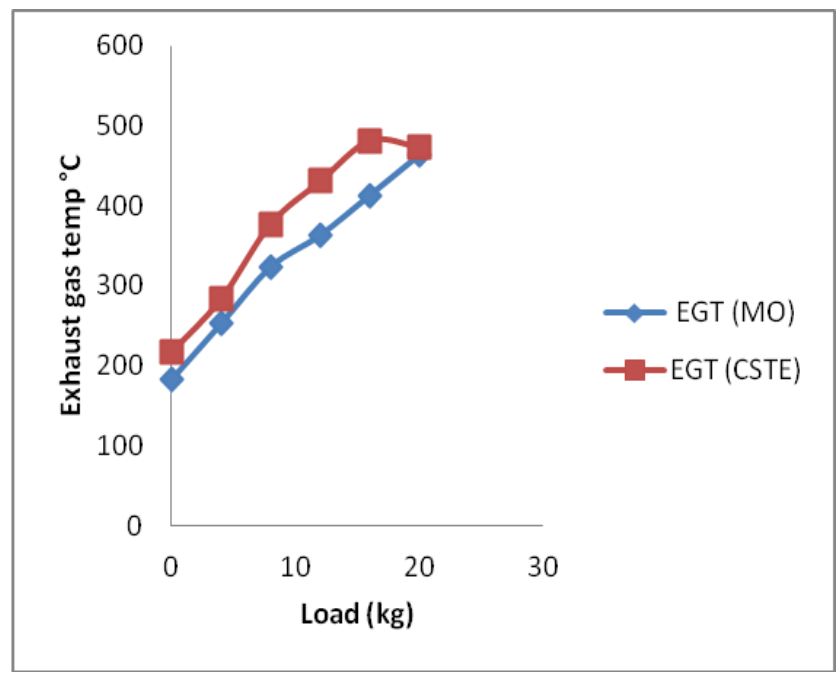

Fig. 10 Engine cooling water outlet temp (WOT).

\subsection{Behavior of lubrication oil.}

The see effect of lubricating oil , surface temperature and engine oil temperature was measured by attaching and inserting thermocouple in engine sump, for 24 hours of

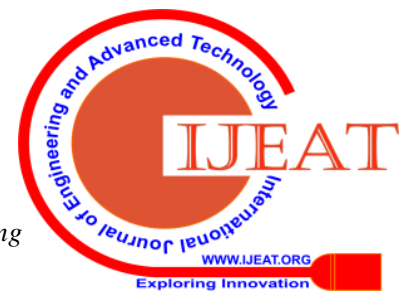


reading shows engine oil surface temperature as well as lubricating oil temperature are within limits and compared these temperature increases and later it get stabilize those we find variation depending on load also, these temperature increases with increasing load and decreases with decreasing load. it was observed that there is small decrease in viscosity also due to $0.5 \%$ dilution of fuel in lubricating oil when test was conducted for 24 hours.. The analysis also showed a reduction in viscosity, the overall fuel consumption is similar to mineral oil and this dilution does not affect much. An assessment of engine condition revealed satisfactory overall appearance, indicating reasonable behavior of lubricating oil as a whole.

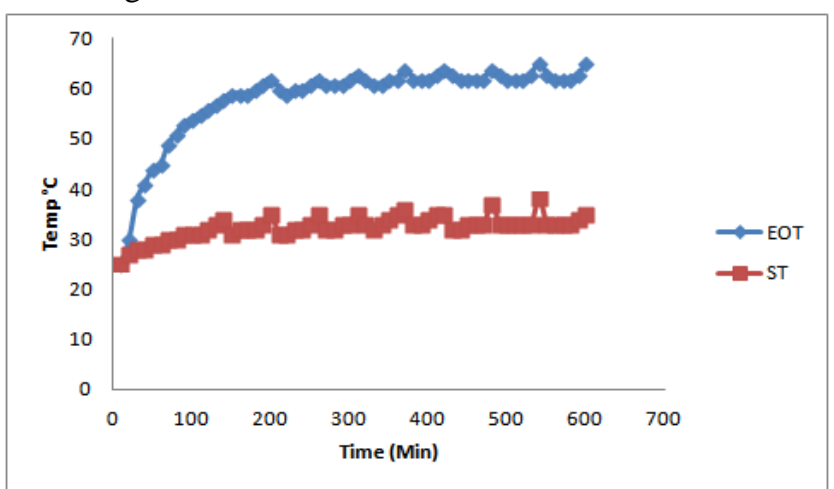

Fig 11 Engine oil lubricant temperature (EOT) and engine surface temperature (ST).

\section{RESULT AND DISCUSSION}

The emission characteristic for example at $12 \mathrm{~kg}$ load on dynamometer show HC of CSTE 33 ppm and for mineral oil is 27.7 ppm HC emission, whereas $\mathrm{CO}$ emission 0.09 ppm and for mineral oil $0.06 \mathrm{ppm}$ and $\mathrm{CO}_{2} 2.85 \mathrm{ppm}$ for CSTE and 2.3 ppm for MO, and $\mathrm{NO}_{\mathrm{x}} 354$ for CSTE and 293 PPM for MO. The emission values are slightly more but close to mineral values indicating CSTE is more stable than pure cottonseed oil and can be used in IC engine.

- HC emissions for mineral oil and CSTE average values are almost the same, there is more HC emissions at low load condition but then it matches with CSTE, at low load condition HC emission is less in CSTE.

- Average CO emission for mineral oil and CSTE is similar at all load conditions

- Average $\mathrm{CO}_{2}$ emission is more for mineral oil at low load condition and then it drop as load increases and again it increases with load whereas for CSTE it increases with load, overall CSTE and mineral oil lubricant has similar $\mathrm{CO}_{2}$ emission though it varies as per load.

- NOx emission for mineral oil and CSTE is same, CSTE has little more than mineral oil at all load conditions.

\section{CONCLUSION}

In the present study, experimental investigation was done in evaluating the feasibility of the use of cottonseed TMP ester oil based lubricants in a diesel engine. Experiments were conducted by using Mineral oil and esterified oil in diesel engine as a lubricant and the results have been compared. It was observed that BTE in the case of esterified cotton seed to mineral base oil are almost the same, in starting phase

oil as ae lubricant was highest followed by mineral oil during part load and the same on full load. Similarly BSFC was lower for the MO oils when compared to the CSTE oil lubricant. Very similar emissions of hydrocarbon (HC) were recorded when running on CSTE and mineral oil lubricants. HC emissions were noted to increase with increased amount of Load on the engine. The fuel consumption of CSTE is 3 $\%$ higher than MO lubricants. The exhaust temperatures for both MO lubricants and CSTE oil lubricants were similar. The analysis of lubricating oil after $24 \mathrm{hr}$ runs showed a very small reduction in oil viscosity caused by fuel dilution. However, the engine oil temperature and engine surface temperature condition showed satisfactory results, indicating reasonable behavior of (CSTE) TMP ester cotton seed oil lubrication.

\section{REFERENCES}

1. Arthur L, miller Christophe B stipe, Matthew C Habjan, Gilbert G. Ahlstrand T, "Role of lubricant oil in particulate emission from hydrogen powered internal combustion engine." Environmental science and technology 2007.

2. H. M. Mobarak E. Niza, Mohamad H. H. Masjuki M. A. Kalam K. A. H. Al Mahmud M. Habibullah A. M. Ashraful, "The prospects of biolubricants as alternatives in automotive applications." Renewable and sustainable Energy Volume 33, may 2014, pages 34-43.

3. N H Jayadas, K Prabhakaran Nair, Ajithkumar, Tribological evaluation of coconut oil as an environment friendly lubricant. Tribology international vol 40, issue 2, February 2007, pages 350 354.

4. Sevim Z Erhan Svajus Asadauskas, Lubricant base-stocks from vegetable oils. Industrial crops and products, Volume-11, issues 2-3, (March 2000) 277-282.

5. Nadia Salih, Jumat Salimon, Emad Yousif and Bashar Mudhaffar Abdullah, Biolubricant base stocks from chemically modified plant oils: ricinoleic acid based-tetraesters, Chemistry Central Journal, 2013, 7:128

6. Andreas Willing, Lubricants based on renewable resources- an environmentally compatible alternative to mineral oil products. Chemosphere volume 43 issue 1 April 2001, 89-98.

7. Jesper Schramm, application of a biodegradable lubricant in a diesel vehicle, SAE technical paper 2003, 01-3111.

8. S. Evim Z Erhan, brajendra k sharma, Joseph m Perez, oxidation and low temperature stability of vegetable oil based lubricant. Industrial crops and product, volume 24, issue 3, November 2006, pages 292 299.

9. S. Bekal and N. R. Bhat. Bio-lubricant as an Alternative to Mineral Oil for a CI Engine-An Experimental Investigation with Pongamia Oil as a Lubricant. Energy sources, part A Recovery, utilization, and Environmental Effect Volume 34, 2012, Issue 11.

10. Mehjabeen Kotwal, Anuj Kumar, Srinivas Darbha, Three dimensional, mesoporous titanosilicate as catalyst for producing bio diesel and bio lubricant. Elsevier, journal of molecular catalysis A chemical 377 2013) 65-73.

11. Quinchia LA, Delgado MA, Valencia C, Franco JM, Gallegos C. Viscosity modification of high-oleic sunflower oil with polymeric additives for the design of new biolubricant formulations. Environ Sci Technol 2009;43:2060-5.

12. Cannon GS, Honary LAT, Soybean based transformer oil and transmission line fluid. Patents US6159913A; 1999.

13. Syahrullail S, Zubil BM, Azwadi CSN, Ridzuan MJM. Experimental evaluation of palm oil as lubricant in cold forward extrusion process. Int J Mech Sci 2011; 53:549-55.

14. Rahim EA, Sasahara H. A study of the effect of palm oil as MQL lubricant on high speed drilling of titanium alloys. Tribol Int 2011;44:309-17.

15. E. Durak, A study on friction behavior of rapeseed oil as an environmentally friendly additive in lubricating oil. Industria Lubrication and Tribology, vol. 56, no. 1, pp. 23-37, 2004.

16. Salimon J, Salih N, Yousif E. Bio-lubricants, raw materials, chemical modifications and environmental benefits. European Journal of Lipid Science and Technology, 2010; 112:519-30. 
17. Rodrigues Jr JDA, Cardoso FDP, Lachter ER, Estevão LRM, Lima E, Nascimento RSV. Correlating chemical structure and physical properties of vegetable oil esters. J Am Oil Chem Soc 2006; 83:3537.

18. K. S. V. Krishna Reddy, Naval Kabra, Umesh Kunchum, and T. Vijayakumar, Experimental Investigation on Usage of Palm Oil as a Lubricant to Substitute Mineral Oil in CI Engines,Volume 2014, Article ID 643521.

19. A. B. Hassan, M. S. Abolarin, A. Nasir, and U. Rachel, Investigation on the use of palm olein as lubrication oil. Leonardo Electronic Journal of Practices and Technologies, no. 8, pp. 1-8, 2006.

20. Ravinarayana Bhat, "A Study on the use of Karanja Oil as Lubrican in Compression Ignition Engines." National Conference on Advances in Mechanical Engineering Science (NCAMES-2016).

21. Siraskar Gulab, "Experimental investigation on usage of cottonseed oil and esterfies cottonseed oil as lubricant in IC engine." Proceedings of $194^{\text {th }}$ the IIER International Conference, Bangkok, Thailand, $5^{\text {th }}-6^{\text {th }}$ October, 2018.

22. Wagner $\mathrm{H}$, Luther R, Mang T. "Lubricant base fluids based on renewable raw materials." their catalytic manufacture and modification. Appl Catal A: Gen 2001; 221:429-42.

23. Hamid HA, Yunus R, Rashid U, Choong TSY, Al-Muhtaseb AaH. "Synthesis of palm oil-based trimethylolpropane ester as potential bio-lubricant. chemical kinetics modeling." Chem Eng J 2012;200202:532-40.

24. Salimon J, Salih N, Yousif E. "Synthesis, characterization and physicochemical properties of oleic acid ether derivatives as biolubricant basestocks.” Journal of Oleo Science 2011; 60:613-8.

25. Salimon J, Salih N, Yousif E. Triester, "Derivatives of oleic acid: the effect of chemical structure on low temperature, thermo-oxidation and tribological properties." Ind Crops Prod 2012; 38:107-14. N.A.

26. Yunus R, Fakhrul Razi A, Ooi TL, Iyuke SE, Idris A. "Preparation and characterization of trimethylolpropane esters from palm kernel oil methyl esters." J Oil Palm Res 2003; 15:42-9.

27. Yunus R, Fakhru'l-Razi A, Ooi TL, Iyuke SE, Perez JM. "Lubrication properties of trimethylolpropane esters based on palm oil and palm kernel oils." European journal of lipid science and technology.2004; 106:52-60.

28. Yunus R, Lye O, Fakhru'l-Razi A, Basri S. "A simple capillary column GC method for analysis of palm oil-based polyol esters." J Am Oil Chem Soc 2002;79:1075-80.

29. Madankar CS, Pradhan S, Naik SN. "Parametric study of reactive extraction of castor seed (Ricinus communis L.) for methyl ester production and its potential use as bio lubricant." Ind Crops Prod 2013;43:283-90.

30. Sripada PK, Sharma RV, Dalai AK. "Comparative study of tribological properties of trimethylolpropane-based biolubricants derived from methyl oleate and canola biodiesel." Ind Crops Prod 2013;50:95-103.

31. Ghazi M, Tinia I, Resul G, Mohamad F, Idris A. Bioenergy II: "production of biodegradable lubricant from Jatropha curcas and trimethylolpropane." Int J Chem React Eng 2009; 7.

32. Silva, J.A.C., "Bio- lubricant production catalyzed by enzymes, Environmentally friendly and bio-based lubricants." Press 2016, Pages 169-185.

\section{AUTHORS PROFILE}

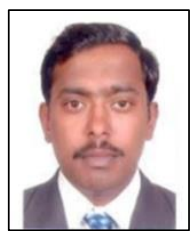

Gulab Siraskar, Amrutvahini college of Engineering (AVCOE), Sangamner, Savitribai Phule Pune University \& Asst. Professor at Pimpri Chinchwad college of Engineering and Research, Ravet, Pune My ORCID id 0000-0003-3796-5116 and my papers Citations is 118,H index 5, I index 5, I have Research experience in University of Tubingen, Germany and having 5 papers to my credit in international journals.

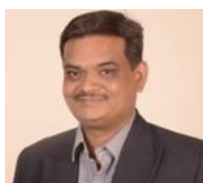

Dr. V. D. Wakchaure, Head of Mechanical Engineering Department, Amrutvahini college of Engineering (AVCOE), Sangamner, Savitribai Phule Pune University, PhD Mechanical Engineering

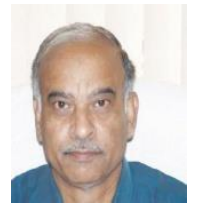

Dr. R.S. Jahagirdar, Phd Guide at Amrutvahin college of Engineering (AVCOE), Sangamner, Savitribai Phule Pune University

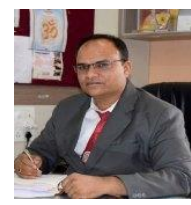

Dr. H.U. Tiwari ${ }^{3}$, Principal, PCCOE\&R, Ravet, Pune. $\mathrm{PhD}$ Mechanical Engineering 